\title{
A path dependence analysis of hospital dominance in China (1949-2018): lessons for primary care strengthening
}

\author{
Jin $\mathrm{Xu}^{1 *}$, Martin Gorsky ${ }^{2}$, Anne Mills ${ }^{3}$
}

1. Peking University China Center for Health Development Studies

2. Centre for History in Public Health, London School of Hygiene \& Tropical Medicine

3. Department of Global Health and Development, Faculty of Public Health and Policy, London School of Hygiene \& Tropical Medicine

\section{* Correspondence:}

Jin Xu, Ph.D., Peking University China Center for Health Development Studies, No. 38, Xueyuan Road, Haidian Distritct, 100191, Beijing, People's Republic of China; email address: xujin@hsc.pku.edu.cn

Key words: hospitals, primary care, history, institutional theory, health systems research

\section{Key messages:}

- We have developed and applied an approach of path dependence analysis that seemed helpful in making sense of the persistence of hospital-centrism in China between 1949 and 2018.

- We have identified two main cycles of path dependence involving a process of "critical juncture — post-juncture development — conjuncture — post-juncture development" since 1949, which started with reinforcement of hospitals' central role in the health system and resulted in the contemporary professional, financial, governance-related and organizational institutions underlying the balance between hospitals and primary care providers.

- As revisionary conjunctures face many challenges of pre-existing hospital dominance, a primary care coalition with strong professional, bureaucratic and community stakes is the key solution to primary care strengthening in China.

- It is important to understand the history of health systems in China, where the challenges of health systems strengthening go beyond limited resources and include different developmental paths as compared to Western countries.

An abbreviated running title: path dependence of hospital dominance in China

\section{Funding}

JX was funded by the China Scholarship Council "National Graduate Students Programme for Constructing Advanced Universities" (201206010317) and Natural Science Foundation of China grant (71804004). The funding bodies did not participate in the design of the study and collection, analysis, and interpretation of data nor in writing the manuscript.

\begin{abstract}
Although China's community health system helped inspire the 1978 Alma Ata Declaration on Health for All, it currently faces the challenge of strengthening primary care in response to hospital sector dominance. As the world reaffirms its commitment towards primary health services, China's recent history provides a salient case study of the issues at stake in optimizing the balance of care. Here we have employed path dependence analysis to explain China's co-evolution of hospital and primary care facilities between 1949 and 2018. We have identified two cycles of path dependent development (19491978, 1978-2018) involving four sets of institutions related to medical professionalization, financing, organisation and governance of health facilities. Both cycles started with a critical juncture amid a radically changing societal context, when institutions favouring hospitals were initiated or renewed, leading to a process of self-reinforcement empowering the hospitals. Later in each cycle, events occurred that modified this hospital dominance. However, pro-primary-care policies during these conjunctures encountered resilience from the existing institutional environment. The result was continued
\end{abstract}


consolidation of hospital authority over the long term. These recurrent constraints suggest that primary care strengthening is unlikely to be successful without a comprehensive set of policy reforms, coordinated and sustained over a prolonged period. Our findings imply that it is important to understand the history of health systems in China, where the challenges of health systems strengthening go beyond limited resources and include different developmental paths as compared to Western countries.

\section{Introduction}

The Astana Declaration on Primary Health Care reaffirmed the world's commitment to primary health care at the fortieth anniversary of the 1978 Declaration of Alma Ata (Global Conference 2018). However, the development of primary care in many low- and middle-income countries faces competition with hospitals for resources (World Health Organization 2008). China has historically provided inspiration for international efforts to strengthen primary care (Litsios 2015). Yet, in recent years efforts to shift the concentration of services and resources in China from hospitals towards primary care have failed (Ma, Wang et al. 2019, Xu and Mills 2019, Yip, Fu et al. 2019).

Our article aims to analyse the evolution of the balance between hospital and primary care facilities in China between 1949 and 2018 from a historical perspective. As Berridge (2011) points out, historical studies can illuminate the processes and relations of power that have moulded the present. Within health systems research, an awareness of history is increasingly recommended so that policy formulation is alert to historically-influenced dynamics (Bloom 2014). Exploration of the historical drivers of hospital dominance therefore provides potentially interesting insights into the underlying challenges facing primary care strengthening. While the focus is China, this study might yield insights for other settings that face similar challenges.

Early historiography of national or comparative health systems concentrated on the structural features of modernisation that brought into being social insurance systems and organised access to health services. Yet neither industrialisation, nor demographic transition, nor the social forces they unleashed, have proven sufficient to explain the timing of their emergence, nor the diversity of health system organisation (Aaron 1967, Collier and Messick 1975, Flora and Alber 1981). More compelling in recent years has been the institutionalist perspective, which instead of treating the state as a neutral setting for conflict between different social formations, sees it rather as an autonomous actor driving events (Hacker 1998). Related to this is path dependence theory, derived from the economics of innovation, and attractive to cross-disciplinary scholars because it proposes generic processes.

At base is the idea that an early 'critical juncture' in policy sets in motion 'feedback effects' that make the ensuing path hard to break away from. The 'increasing returns' of a policy choice might include popular accustomisation, expansionary momentum driven by bureaucrats, institutional adaptation, and invested civil society lobby groups (Pierson 1993, Hacker 1998, Pierson and Skocpol 2002). Through these, policy 'lock-in' occurs, so that even when sub-optimal features become apparent, the political costs of change appear greater than that of persistence. Current policy choices are therefore circumscribed by previous decisions (Pierson 2000). Potentially, we may apply path dependence approaches to understand China's balance of care.

What is at stake in transposing this analytical mode, derived from the Western democracies, onto China post-1949? Differences in governing structures and the role of civil society mean that a comparable pluralistic arena of policy-making does not obtain. Nonetheless, several studies have taken long-run approaches to charting the emergence of China's hospitals and primary care that are compatible with path dependence analysis. For example, Renshaw's study of China's hospital system since the nineteenth century showed how patient preferences for institutional care resulted from a long process of acculturation (Renshaw 2014). Lucas demonstrated 'policy continuities' in community care, from interwar social medicine experiments up until the Cultural Revolution (Lucas 1982). Our own earlier work examined the long-run process by which hospital-based Western biomedicine arrived in China, 
and its limited capacity to meet public health needs of its large population as rural development became prioritized (Xu, Gorsky et al. 2019). Duckett's study of health welfare policy since Mao demonstrated that different levels of institutionalization led to contrasting outcomes of urban and rural health financing, when government attempted to cut back on welfare provision (Duckett 2012). Finally, path dependence has been invoked to characterise an Asian 'market-Leninist' welfare regime, where socialist traits are carried forward into the commercialization era after economic reform (London 2014).

There are therefore reasonable empirical grounds for pursuing this approach in the Chinese context. We stress at the outset that our account concentrates on the role of state institutions in shaping the configuration of services, and within the confines of a short article do not attempt to span the full range of factors. These range from the contextual - such the pace of economic growth and the developmental trajectory of the biomedical profession - to the role of individual agency. Next, we elaborate our framework and methodology.

\section{Methods}

\section{Path dependence analysis}

We draw from previous path dependence analyses and adopt the concepts of "critical junctures", "conjunctures" and "post-juncture development" for the temporal framing of historical processes. Here, critical junctures refer to important windows of opportunity, driven by changes mainly outside of health systems that require adaption of health policies and system actors. Despite likely strong resistance against policy changes, there can also be "conjunctures", where the coming together of events substantially challenge or even reverse existing policies (Wilsford 1994). Hence, conjunctures here refer to health policy windows opened by deliberate changes that revise the previous balance between hospitals and primary care facilities. During the intervals between the key policy episodes (i.e. critical junctures and conjunctures), the internal processes of the previous systems, dubbed by Tuohy (1999) "system logics", play out. In our study, post-juncture development refers to the downstream events that follow the critical junctures or conjunctures.

Table 1. Analytical steps for path dependence analysis

\begin{tabular}{ll}
\hline Step & Content \\
\hline $\mathbf{1}$ & Clarify the unit of analysis \\
\hline $\mathbf{2}$ & Clarify chronological scope and periodization \\
\hline $\mathbf{3}$ & Extraction of historical background \\
\hline $\mathbf{4}$ & Extraction of political structure \\
\hline $\mathbf{5}$ & $\begin{array}{l}\text { Preliminary identification of main actors and extraction of their actions and interactions } \\
\text { during the periods of interest }\end{array}$ \\
\hline $\mathbf{6}$ & $\begin{array}{l}\text { Identify “candidate" critical junctures and select for analysis the most consequential critical } \\
\text { junctures }\end{array}$ \\
\hline $\mathbf{7}$ & Identify “candidate" conjunctures and select for analysis the most consequential conjunctures \\
\hline $\mathbf{8}$ & Reconstruct the key historical processes following their temporal sequence
\end{tabular}

Source: adapted from (Capoccia 2015) with substantial modification

We applied a protocol as shown in Table 1, modified from Capoccia's suggested approach to critical juncture analysis (Capoccia 2015), and conducted our analysis iteratively. Our units of analysis are the complex of professional, organizational, financial and governance institutions related to hospitals and primary care providers, which constituted the key components in the coevolution of both types of facility. We then clarified the historical background and political structure of each period, with the main actors, 
their actions and interactions. Next, we identified critical junctures and conjunctures. The remaining temporal segments in between were categorized as post-juncture development periods. Lastly, we reconstructed the key historical process using the structure provided, following their temporal sequence. We now describe how we segmented the history and identified key periods, along with a brief account of the historical context.

\section{Economic and political background}

Our analysis starts with the founding of the People's Republic of China in 1949, after which China moved from post-war restoration to launching an urban-focused industrialization scheme in 1953. As we will demonstrate, 1949-1953 constituted a critical juncture, as an urban hospital focus was established in the new republic. A planned economy was developed with a profound urban-rural divide, in which social welfare was largely exclusive to the urban population. In the late 1960s, the country's leaders emphasized egalitarian ideology and advocated class struggle as the central policy (MacFarquhar and Fairbank 1987, MacFarquhar and Fairbank 1991), introducing a conjuncture (1965-1968) when rural primary medical services extended nationwide.

The analysis is punctuated by the year 1978, which marked China's historical pivot from a model of development based on the planned economy to one based on a market economy. After 1978, collective agriculture was dismantled, along with rural health risk-pooling schemes, introducing the 1978-1985 critical juncture, which ended with a clear shift towards commercialization in health. The share of government finance in total expenditures for health dropped continuously until 2002, when a conjuncture emerged, until 2009 when a comprehensive health reform was launched.

Throughout the 70 years studied, China achieved substantial economic growth, accompanied by greater health service resources. The number of doctors per thousand people increased from 0.62 to 2.31 , 1949-2016, and beds per thousand rose from 0.19 to 5.36 (National Health and Family Planning Commission 2017). In urban areas, there were ministerial, provincial, municipal and district hospitals, as well as community health institutions in 2018; in rural areas, there were county hospitals, township health centres and village clinics. Although county hospitals were based in the county's capital town, they were typically categorized as rural facilities.

While central and local health agencies were the main governmental bodies in charge of health facilities, other government bodies responsible for finance, personnel, price and planning controlled critical elements of health policies (Bloom 2004). Furthermore, local governments controlled a significant proportion of public spending, and from the mid-1980s to the early 2000s their priority was not health but economic development (Gusmano 2015). Key civil society stakeholders might gain the sympathy of state bureaucrats, but they were not directly involved in policy making within the state. Most crucially, the Chinese Medical Association was annexed by the Ministry of Health after 1949 (Chen 1989).

\section{Data sources}

We used a range of materials. Several texts chronicled medicine-related and contextual events for the period studied (Chen and Xu 1984, Deng and Cheng 2000). We also analysed official documentation of historical statistics and compiled policy documents produced by the Ministry of Health (National Family Planning and Health Commission since 2013) and three provincial health gazettes. Published memoirs of key actors were collected and analysed. Journals and newspapers were searched and read, including the People's Daily and Chinese Medical Journal. Although we mainly relied on secondary sources, we also explored two local archives, as national archives were inaccessible for post-1949 periods. The lead author accessed the Beijing Municipal Archive and the Archive of Pinggu. Pinggu is a suburban district of Beijing and used to be a rural county before 2001. The documents from official sources (e.g. yearbooks) and archival materials opened to us were mainly bureaucratic texts, with a consequently narrow and official representation of events, and did not necessarily reflect the actual practice. Occasionally though, they did provide unexpected insights into the varied perspectives of bureaucrats at different levels. We triangulated these materials with secondary sources. 


\section{Results}

\section{Development of a two-sector system of service delivery (1949-1978)}

\section{Launching urban-biased welfare (1949-1953)}

In 1949, the health service providers in China consisted of urban-focused private medical practitioners and hospitals, and public rural primary care facilities, complemented by rural native practitioners of traditional healing. While most doctors were private (Ministry of Health 1989), the basic structure of the public system reflected two parallel development trajectories of a professionalized hospital and public health system, alongside diverse and fragmented private practitioners (Xu, Gorsky et al. 2019). After 1949, China adopted the Soviet Model of economic and social development and launched its first five-year plan in 1953. This sweeping change of focus from its previous rural-based revolution to urban-centred development (Mao 1949) opened a critical juncture for the co-evolution of primary care providers and hospitals.

Between 1949 and 1953, institutions leaning towards the development of hospitals in urban areas were either introduced or reinforced. Organisationally, hospitals previously under the Nationalist Administration and foreign missionaries were taken over by the new Communist regime (Jiangxi Provincial Health Gazette Compiling Committee 1997). Hospitals maintained the direct-access outpatient departments created before 1949 (Xu, Gorsky et al. 2019). Financially, one of the most salient events was the initiation of Soviet-style workers' and civil servants' insurance, respectively the Labour Insurance Scheme (LIS) and the Government Insurance Scheme (GIS), in urban areas (Hu 2012). Private practitioners were either incorporated into hospitals or grouped into united clinics, whose revenue relied solely on fee paying patients (Ministry of Health 1951), and hospitals were the predominant recipients of the insurance funds. For the profession, medical education reform with a Soviet-style early clinical specialization and shorter school years produced graduates poorly equipped to practice general or family medicine, and bound qualified doctors to hospitals (Ministry of Health 1951, Zhang 1953, Qian 1988).

In rural areas, the government prioritized preventive medicine and local resources remained meagre. The Ministry of Health (MOH) repeatedly stressed that the priority of county ${ }^{1}$ and sub-county health facilities was not to provide curative care but to function as a base for all aspects of health work and to organize a local health workforce to provide preventive services (i.e. guidance and training in epidemic prevention and maternal and child health care) (Ministry of Health 1950, Ministry of Health 1951). By 1949, the life expectancy at birth was only 35 years, the infant mortality rate was 200 per 1000 live births, and the maternal mortality ratio was 1500 per 100,000 live births. Infectious diseases were estimated to contribute to $70 \%$ of the loss in life expectancy (Wang, Yu et al. 2015). Due to such problems as illiteracy, superstition and poor transportation, health campaigns faced challenges in rural areas, and the preventive focus continued to be justifiable (Zhang 1950). According to official propaganda, the prioritization of medical care benefits for the urban population was a rational short-term strategy given limited resources, and would eventually lead to expansion of coverage to the countryside (Zhang 1953).

Thus, the consequence of this initial critical juncture of 1949-1953 was a health system with separate financing, service delivery, professionalization and accountability for rural and urban health services. The institutional complex that would essentially last for more than six decades was formed: a professional bias towards a hospital-based career; blurred organisational boundaries that precluded dependence of hospitals on referrals from primary care doctors; a financing bias towards hospital services; and a governance bias where hospital secured a strong political base through their beneficiaries. These four sets of institutions underpinned the model of hospital dominance which became adaptively

${ }^{1}$ Counties have been an important basic level of administration in China, where residents are predominantly rural. Central and provincial policies are usually tailed to local circumstances at the county level. Although county health centres (later county hospitals) were based in county seats, which were towns, they were classified as rural health facilities as they were supposed to serve their local (i.e. mainly rural) population. 
self-reinforcing.

\section{Self-reinforcing development of urban hospitals (1953-1965)}

Once established, the institutional biases towards urban hospitals prompted a dynamic post-juncture process. Insurance coverage led to increased demand for hospital services, while the ability of urbanites (wealthier compared to rural population) to pay out-of-pocket also increased hospital utilisation and the expenditures of urban insurance schemes rose, resulting in continuous deficits of the funds (Cao 1955, Yin 1955, Huang 1957, Liu 1957). The MOH attempted to introduce regional referral networks between urban hospitals and primary care facilities (Ministry of Health 1957), however, weak primary care capacity and self-funding urban patients inhibited the effectiveness of referral policies in shifting care away from hospitals (Ministry of Health 1957). To cope with growing demand, the MOH introduced lower-cost substitutes for hospitalisations, including lowered charges and enlarged hospital-based outpatient departments (Ministry of Health 1962). As compensation, hospitals received subsidy from 1954 by retaining a "pharmaceutical sales mark-up", i.e. a fixed $15 \%$ margin on top of purchased prices of pharmaceuticals (Zhang and Bian 2007). State-owned enterprises (SOEs) developed their industryspecific health delivery systems independently from the $\mathrm{MOH}$, employing numbers of health workers equal to about $40 \%$ of those of MOH facilities in 1957 (Ministry of Health 1989). In short, the postjunctural development saw hospitals expand organisationally into ambulatory services for common illnesses, which could otherwise have been the basis for developing general practice, while their increased reliance on pharmaceutical mark-ups and their growth of hospitals in the industrial sector seeded further fragmentation in hospital governance.

Meanwhile, alongside rural collectivization from the late 1950s to 1965, rural medical services were being reinforced. These included county hospitals (restructured from county health centres), commune health centres (established around 1958, mainly restructured from united clinics), and village health workers (peasants with brief training). The $\mathrm{MOH}$ focused its financial commitment on county hospitals, prompting a rapidly growing number of doctors in these institutions, from 7,454 in 1952 to 52,033 in 1965 (Ministry of Health 1989). At the same time, the MOH encouraged county governments, rural communes and privately-paying patients to fund primary care providers (Ministry of Health 1957, Ministry of Health 1959, Ministry of Health 1960, Ministry of Health 1962, Ministry of Health 1965). The aftermath of the Great Leap Forward included the continued heavy epidemic disease burden and maternal and child health needs that prompted government to allow more flexible use of a medical relief fund for maternal and child health also to cover severe infectious diseases (State Council 1963). Mortality rate doubled from 12.28 per thousand population in 1950 to 25.43 per thousand population (National Health and Family Planning Commission 2017). Three conditions, namely edema, gynaecological problems and child malnutrition were particularly prevalent (Zhou 2016). The higher priority given to preventive services in rural areas likely also contributed to the relative neglect of curative primary care compared to urban hospital services in governments' financial commitments.

Overall, post-junctural development generally consolidated the embedding of hospitals in the urban socio-economy, and primary care facilities in the rural socio-economy.

\section{Turning towards rural primary care (1965-1968)}

The convergence of major political events between 1965 and 1968 disrupted the system logic of reinforcing urban hospitals, producing a conjuncture favourable to primary care strengthening. In 1965, in the "26th June Directive" which was later widely circulated, Chairman Mao reprimanded the MOH for ignoring rural health (Zhang 2006). The MOH duly issued a plan to shift the focus of health work to rural areas, including organising many hospital-based doctors into mobile medical teams to deliver rural care and train village-based "half-peasants-half-doctors", i.e. peasants with very short-term and simple medical training (Commentator 1965).

Rural health was further politicized during the Cultural Revolution (1966-1976), with more doctors sent down to work in rural areas for long durations, though many were able to remain close to urban facilities as Lucas' analysis of 68 reports on mobile medical teams suggested (Lucas 1982). Furthermore, the regime scaled up nationwide a rural community health risk-pooling scheme--the Cooperative 
Medical Scheme (CMS), with short-term training for community health workers, dubbed "barefoot doctors" (Editorial Office of the Red Flag Magazine 1968, Revolutionary Committee of Leyuan Commune 1968). They were predominantly selected from local poor peasants' families, received minimal medical training (from several weeks initially to about 2-3 years), acted as the first-contact provider for villages for most curative and preventive services, and were paid by their work points as a member of the agricultural collective. It is worth noting here that the barefoot doctor programme was as much a response to demand for health care in low-resource rural areas from the bottom up as a national model promoted from above (Zhou 2016, Gross 2018).

The policy change was not just about substance but also discourse, representing the ideology of the Cultural Revolution. According to a 1968 article promoting the CMS endorsed by Mao, "poor and lowermiddle peasants should hold the power of rural medicine" (Revolutionary Committee of Leyuan Commune 1968). The urban doctors mobilised to work in rural areas were not to be the experts, but rather were considered an ideologically compromised bourgeois, in need of re-education to serve the majority population of peasants. Among their key tasks was to facilitate the training of the new health workforce, the barefoot doctors. The emphasis on leadership of the peasants essentially reinforced a community-based, low-cost model of health delivery and ruled out a strong bureaucratic stake (i.e. ministerial leadership) in rural health development. Essentially, the barefoot doctor programme and the Cooperative Medical Scheme constituted an echo of the 1930s community health approach initiated in state medicine (Xu, Gorsky et al. 2019).

\section{Resistance and adaptation during implementation (1968-1978)}

The conjunctural efforts eventually extended primary care coverage to most of the country's population, but were constrained by the system logic already established at the 1949-1953 critical juncture. The CMS's level of benefits and provider payment were not comparable with those of the urban insurance schemes, though it did receive some government fiscal support in the 1970s (Ministry of Health 1974). In reality, at least some of the urban-trained doctors were providing important support in the development of barefoot doctors under the peculiar circumstances of the Cultural Revolution (Gross 2018). This reliance of primary care professional training on the extreme circumstances of the Cultural Revolution reflected the prior lack of institutionalization and the challenge of reorienting the medical education system towards rural primary care. There was resistance to efforts to shift urban human resources to rural areas, given the pro-urban financing and organisational institutions established in the 1950s. For instance, the Beijing Municipal Health Bureau (1973, 1973) proposed postponing posting away urban medical professionals, as urban hospitals suffered from serious overload and chaos affecting "care-seeking of workers and peasants" due to staff shortages. Nation-wide, the proportion of doctors in urban areas and urban hospitals was consistently higher than in rural areas between 1965 and 1975, with the gap widening between 1970 and 1976 (Ministry of Health 1989).

Within rural health facilities, the increase in the numbers of county hospital professionals slowed, and township health centres received substantially more college-trained doctors after 1968 (Ministry of Health 1989). However, this did not simply mean primary care strengthening. Township health centres were developed into miniature hospitals to extend substantial clinical services to rural residents, and had 0.7 million beds by 1978, compared to 1 million in all hospitals (including both urban and county) (National Health and Family Planning Commission 2017). Wider reform of medical education during the Cultural Revolution failed, with formal medical training shortened to three years and students recruited with little prior education, producing poorly trained graduates (Luo and Sun 1992). These graduates were not capable of establishing rural primary care on an equal professional status with hospital doctors. Furthermore, few of these graduates had begun as barefoot doctors. $71 \%$ of all the 1,652 barefoot doctors who had worked in Pinggu since 1965 remained as barefoot doctors by 1975, while only 132 had left for further education, not necessarily related to medicine (Pinggu Health Bureau 1975).

Thus, technical upgrading of medicines and services provided by the barefoot doctors was very limited, and indeed not seen as worthwhile by the radical political leaders under the ideological climate of the Cultural Revolution. Instead, given the severe resource constraints, a political campaign was launched in support of cheaper traditional healing through Chinese herbal medicine and acupuncture. From 1972, growing herbal remedies for self-sufficiency, and training barefoot doctors in acupuncture, 
were encouraged. For instance, 67 local herbal pharmacies were built in Pinggu County (Pinggu Health Bureau 1986). Evidence suggests public reaction varied substantially. Local party spokespeople during the Cultural Revolution claimed that patients were satisfied with herbal medicine (Party Branch of Heidouyu Brigade at Huangsongyu Commune 1977). However, recent local oral history evidence suggests that far from trusting herbal therapies, many preferred Western medicines, which usually offered faster resolution (Fang 2012). It is probable that not all the rural population appreciated the value of low-cost primary care. However, propaganda during the Cultural Revolution lauded the CMS and the barefoot doctors as new models of health services, making it difficult to criticise their limited range and quality of drugs and services. Indeed, Deng Xiaoping (who after 1978 replaced Mao as China's top leader) was attacked by radicals as ideologically wrong in 1974 for saying to foreign visitors that barefoot doctors would be upgraded into professionals (Zhang and Unschuld 2008). It thus seems that the earlier association of professional education with privileged urban class made it ideologically challenging to integrate them into the new model of rural primary care.

Overall, the 1968-1978 post-juncture developments saw resilience of the pro-hospital institutions in urban areas laid down in the 1950s, and rural primary care established as the antithesis of hospitals. Rural primary care was weakly institutionalized amongst professionals, ultimately producing reversion to the earlier trajectory. Moreover, rural primary care and urban hospitals provided an overlapping range of services (both inpatient and ambulatory), foreshadowing later competition. Despite these issues, an epidemiologic transition took place during the Maoist period. In 1981, life expectancy at birth reached 67.9 years (up from 35 years in 1949), and the infant mortality rate fell to 34.7 per 1000 live births (compared to 200 per 1000 live births in 1949) (National Health and Family Planning Commission 2017).

\section{Adaption and path dependence during reforms (1978-2018)}

\section{Changes favouring hospitals and technology (1978-1985)}

After 1978, as China entered a social transition towards a market economy, health policies had to adapt to new circumstances. Health policy makers were challenged by public funding constraints and increased requirements for technological advancement (Henderson 1989). They also faced a sharp increase in demand for health care from a rapidly urbanizing population (National Bureau of Statistics of China 2012). The collapse of the agrarian collective economy meant additional difficulty in sustaining rural health services. Decisions on how to address these challenges created another critical juncture.

The previous strong bureaucratic orientation of the $\mathrm{MOH}$ and established professional institutions favoring hospitals contributed to the dominance of a strong hospital-bias in the MOH's policy response to the situation. First, the MOH actively restored the technical capacity of hospitals believed to have been harmed during the Cultural Revolution (Tang and Meng 2004). Priorities were given to establishing advanced medical centres as regional technical centres (Henderson 1989) and strengthening county hospitals (Ministry of Health 1980, Ministry of Health 1980).

Second, financing reform was implemented to address health facility deficits, mainly to the benefit of hospitals. As the CMS collapsed along with collective agriculture (Duckett 2012), the MOH allowed privatization of village clinics (State Council 1985). It tightened budgetary constraints on public health facilities and encouraged them to seek extra-budgetary revenue by allowing management autonomy to redistribute surplus (Ministy of Health, Ministry of Finance et al. 1979, State Council 1985). Non-basic services (principally technological interventions) started to be priced above cost (Liu, Liu et al. 2000) in order to subsidize health facilities. These policies benefited hospitals in both capital development and clinicians' incomes (Pinggu Health Bureau 1986, Liu, Xu et al. 1996).

Third, human resource policies reinforced the hospitals' advantage. Pre-Cultural-Revolution hierarchies were restored in medical colleges in 1977, supplying hospitals with an ever larger number of doctors (Editorial 1977). Township health centres experienced an immediate exodus of their best doctors due to lack of income, benefits and professional prospects (Zhang 1982). The MOH abolished the title of "barefoot doctor" in 1985 and kept only 0.6 million "village doctors" who passed a certification examination (State Council 1981, Ministry of Health 1989). 
With the clear establishment of market-oriented reform, 1985 marked the completion of the critical juncture underway since 1978. After the Cultural Revolution, the MOH reverted back to prioritising hospitals, partially restoring the situation in the early 1950s. There was little organized rural action against the fall of the CMS, probably due to its embeddedness in collective agriculture - something rural residents seemed ready to sacrifice in a fundamental decollectivization reform (Duckett 2012). Policies addressed the short-term financial needs of hospitals by allowing greater autonomy in revenue generation, surplus retention and internal distribution. In contrast, rural health financing and human resources were allowed to deteriorate rapidly, underlining the limitations of the prior efforts to strengthen primary care.

\section{Evolution of the two-sector structure (1985-2002)}

A dynamic post-juncture process quickly unfolded, along with further commercialization policies (State Council 1989, State Council 1992, State Council 2000). Revenue-based bonuses were adopted in health facilities to incentivize doctors to provide more services and facility managers to increase service efficiency (Liu and Mills 2005). A new Urban Employee Basic Medical Insurance Scheme replaced the original LIS and the requirement for referral to hospital services was replaced with competition across all levels of care (State Council 1998). Although recognizing the severe challenges facing rural primary care, the $\mathrm{MOH}$ failed to either secure direct fiscal subsidy or re-establish risk-pooling funds (Ministry of Health 1990, General Office of Central Committee of Communist Party of China and General Office of State Council 1993).

The set of financial incentives for revenue generation mentioned above, together with enhanced competition between facilities, encouraged hospital managers and doctors to adopt expensive technological procedures and medicines and induce unnecessary medical demand and utilisation (Liu and Mills 2005). Both the numbers of beds and hospital doctors increased by more than $50 \%, 1985$ to 2002 (National Health and Family Planning Commission 2017). A medical equipment race emerged as a result of competition for the revenue that could be gained from high-technology medicine. Reports from local areas suggested that the number of CT scanners in hospitals amounted to 3 to 8 times the planned quota (Li 1997). Public hospitals achieved such development with little direct government subsidy (about 7.6\% of total hospital revenue by 2002) (Ministry of Health 2003). Pharmaceutical sales accounted for $47 \%$ of the total revenue of comprehensive hospitals under health departments (Ministry of Health 2003).

While village doctors generally lost the support from the CMS and relied on profits from drug sales to earn a living (Bloom 1998), township health centres were trapped in a vicious cycle of underutilisation and financial deficits (Liu, Xu et al. 1996). Dangerous premises, outdated equipment and shortages of professionals were commonplace among them (Liu, Xu et al. 1996). Their proportion of staff lacking qualifications rose from 40\% in 1983 to 58\% in 1988 (National Bureau of Statistics of China 1989).

Overall, the period from 1985 to 2002 witnessed a continuous downstream evolution of an institutional balance that favoured hospitals. Failed efforts to bring back the CMS and secure substantial budget allocation for primary care facilities during this period meant the primary care facilities, in order to survive financially, had to compete directly with hospitals for patients, and hospitals continued to benefit from the institutional primacy established in the 1950s. The two-sector model of urban hospitalfocus and rural primary-care-focus started to be converted to a model where hospitals became dominant overall. During this period, there was evidence that chronic, non-communicable diseases (NCDs) had become the main cause of premature death and morbidity, which implied the importance of stronger primary care to prevent NCDs and manage conditions at early stages of disease progression (World Bank 1992). However, the inability to strengthen primary care around the end of the 21 st century paved the way towards rapidly increasing pressure on health services from chronic patients after 2000.

\section{Turning towards universal health coverage (2002-2009)}

The period from 2002 to 2009 constituted another conjuncture. An outbreak of Severe Acute Respiratory Syndrome (SARS) spread to 24 provinces within 2 months in mainland China (Wang, Yu et al. 2015). The outbreak presented a huge risk to macroeconomic stability, revealing the danger of 
neglecting health security, and adding weight to international criticism of China's lack of health riskpooling (World Health Organization 2000). A new administration highlighted the importance of heath along with improved social welfare, and launched two major social health insurance schemes for previously uncovered urban and rural residents. In 2009 it implemented a milestone reform aiming at achieving universal basic health coverage by 2020 (Central Committee of Communist Party of China and State Council 2009). Primary care strengthening was an important component of the reform, with the goal of satisfying the demand for services addressing all common illnesses at primary care facilities.

As the social health insurance schemes rolled out, the share of out-of-pocket payment in total health expenditures reduced from $60 \%$ in 2001 to $37.5 \%$ in 2009 (China National Health Development Research Center 2017). However, greater financial leverage was not used effectively to strengthen primary care. Social health insurance prioritized reimbursement for hospitalizations (Yip and Hsiao 2009) and further encouraged competition among providers (Ministry of Health, Ministry of Finance et al. 2007). Besides, while subsidies were provided to primary care facilities (as well as hospitals), the reform also introduced a payroll cap for primary care, reducing the financial motivation for expanding clinical services (State Council 2009).

Community health services institutions developed rapidly and became ubiquitous primary care facilities in urban areas (Bhattacharyya, Yin et al. 2011). However, their prescriptions were limited to essential drugs (State Council 2009). A new set of essential public health services, with performance targets focusing on number of services rather than outcomes, were introduced as a key responsibility of primary care facilities (State Council 2009), competing with staff time for clinical care. The reform masterplan emphasised the training of general practitioners for primary care facilities (State Council 2009). In terms of governance, while policies on primary care reform were to be implemented immediately, the $\mathrm{MOH}$ had limited ability to control hospital behavior, reflecting fragmented policy making and the imbalance in power between hospitals and primary care facilities.

Overall, the 2002-2009 conjuncture saw primary care strengthening clearly put on the policy and financing agenda, though some restrictive financial and organisational policies ran counter to their development; meanwhile, the power of hospitals to generate revenue was not constrained.

\section{Increasing hospital dominance amid health system reform (2009-2018)}

In the post-junctural development, social health insurance schemes reached almost universal coverage, and out-of-pocket payment further reduced, from $37.5 \%$ in 2009 to $28.8 \%$ in 2016 (China National Health Development Research Center 2017). However, the hospital-centric structure introduced in the early 1950s and reinvigorated after 1978 proved difficult to revise. The health system thus seemed to experience a "lock-in", as resources and patients became increasingly concentrated in hospitals despite the reform's aim of primary care strengthening.

The medical schools started to reform higher medical education with early specialization and introduced general practice programmes, but graduates did not see primary care as a promising career. A survey of 546 medical graduates from a prestigious medical school showed that none went to primary care facilities (Fu 2011). Another study on a special contract-based programme targeting rural facilities showed that only $1.6 \%$ of graduates eventually employed in primary care facilities after graduation liked their work (Hu, Chen et al. 2018). The difficulty these new graduates had in finding satisfactory jobs in general practice was attributable to the long-term orientation of medical professionalisation towards hospitals consolidated in the 1950s.

Financing reform aiming at decommercialisation faced greater implementation challenges in hospitals than in primary care. Most provinces started to remove drug mark-ups in public hospitals in 2017-eight years after this started in primary care facilities (National Health and Family Planning Commission, Ministry of Finance et al. 2017). The delay was probably attributable to the fragmentation of decision-making among multiple ministries responsible for either providing an additional funding subsidy or increasing the prices of physician services to replace the markup in cost recovery. Hence, the hospital share of pharmaceutical revenue in all health facilities grew from $61.6 \%$ to $76.3 \%$ between 2009 and 2016, and this funding stream accounted for more than a third of hospital revenue (China National 
Health Development Research Center 2017, National Health and Family Planning Commission 2017). The actions of corporate interests seemed to make reform more challenging. Scandals about "kickbacks" that drug manufacturers and distributers gave doctors to promote their products further revealed that reliance on the drug distribution system to cross-subsidize physicians had significantly normalized such illegal practice (Huang 2013, Zheng 2013). Organisationally, integrated delivery systems were established across various levels of facilities, with the intention that hospitals would support primary care providers. However, the hospitals were uninterested in building such capacity of primary care providers, as their income would suffer if patients went instead to primary care (Liang, He et al. 2016).

Self-reinforcing dynamics unfolded. There was low patient confidence in, and low demand for, primary care services (Wang, Gusmano et al. 2011), due to previous lack of highly-qualified primary care professionals--a result of long-standing medical education policies. The growing income gap between hospital doctors and primary care doctors due to asymmetric reform development also contributed to reduced motivation of some professionals to work in primary medical care, eventually giving rise to a brain drain of experienced doctors to hospitals (Zhou, Li et al. 2014). Motivation to provide medical services was affected by the fixed salary for primary care facilities, while additional resources disproportionately flowed towards hospitals, following the increasing volume of services $(\mathrm{Xu}$ and Mills 2017).

Towards the end of the period, a number of policy revisions took place. A new National Healthcare Security Administration was established, incorporating the functions of pricing, procurement and payment for all insurance schemes (Central Committee of Communist Party of China 2018). Such an integrated governance structure of financing could permit strategic purchasing to shift the balance towards primary care. Policies on enhancing the professional standard, status and salary of general practice were also issued (General Office of the State Council 2018). Several policies restricting the development of primary care facilities were removed or loosened. For instance, Beijing standardised the pharmaceutical catalogue across primary care facilities and secondary hospitals (Beijing Municipal Government 2017), essentially lifting prescription restrictions for primary care facilities. How these latest policy changes will influence the balance of care remains to be seen, and it is clear that resources and services continued to be concentrated in hospitals (Xu and Mills 2019)

\section{Discussion}

\section{Limitations and strengths}

As the study is about overall historical processes, we have had to limit our analysis to the most typical and available cases at an aggregate level. Huge variations exist in China and cannot be well captured within the space of this article. Another important limitation is our restricted access to historical archives and lack of use of oral history, so we mainly built our analysis on secondary sources and official publications. This restricted our ability to detect the agency of some key individuals and organisations. Nevertheless, the study was innovative in bringing an historical-institutionalist lens to China's contemporary problem of hospital dominance.

\section{Findings}

Following our analytical framework, Table 2 summarises the dynamics in China of the coevolution of hospitals and primary care providers from 1949 to 2018 as two path-dependent cycles. 
Table 2. Historical logic of coevolution of hospitals and primary care providers in China (1949-2018)

\begin{tabular}{lll}
\hline $\begin{array}{l}\text { Path } \\
\text { dependence } \\
\text { stages }\end{array}$ & $\mathbf{1 9 4 9 - 1 9 7 8}$ & $\mathbf{1 9 7 8 - 2 0 1 8}$ \\
\hline $\begin{array}{l}\text { Critical } \\
\text { juncture }\end{array}$ & $\begin{array}{l}\text { 1949-1953: Government priority in health } \\
\text { development shifted towards urban insurance } \\
\text { and urban hospitals, which created strong } \\
\text { interest coalitions with hospitals. Rural health } \\
\text { care focused on preventive care and did not } \\
\text { the introduction of strong financial incentives to } \\
\text { benefit from the new insurance schemes. }\end{array}$ & $\begin{array}{l}\text { subsidization from hedicines. The structure favoured hospital } \\
\text { development, while rural reform left the collective- } \\
\text { based and weakly institutionalized rural primary } \\
\text { care facilities in a vicious cycle of under- } \\
\text { development. }\end{array}$ \\
& &
\end{tabular}

\begin{tabular}{|c|c|c|}
\hline $\begin{array}{l}\text { Post- } \\
\text { juncture } \\
\text { development }\end{array}$ & $\begin{array}{l}\text { 1953-1965: Urban demand for hospitals grew, } \\
\text { prompting further expansion of outpatient } \\
\text { departments and industrial health services. } \\
\text { Cheap and de-professionalized primary care } \\
\text { started to be developed in rural areas, along } \\
\text { with collectivization. The embedding of } \\
\text { hospitals in urban socio-economy and primary } \\
\text { care facilities in rural socio-economy became } \\
\text { consolidated. }\end{array}$ & $\begin{array}{l}\text { 1985-2002: Increased hospital autonomy and } \\
\text { limited financial subsidies drove hospitals to } \\
\text { develop a model based on heavy use of } \\
\text { technologies and expensive medicines, while the } \\
\text { primary care sector suffered from continued } \\
\text { financial difficulties; rapidly widening gaps } \\
\text { between primary care and hospital facilities. }\end{array}$ \\
\hline Conjuncture & $\begin{array}{l}\text { 1965-1968: The "June 26th Directive" pushed } \\
\text { for the prioritization of rural health care, sent } \\
\text { urban doctors to rural areas, popularized the } \\
\text { rural Cooperative Medical Scheme and } \\
\text { barefoot doctors. The rural primary care } \\
\text { program became rhetorically re-established on } \\
\text { the ideology of Cultural Revolution. }\end{array}$ & $\begin{array}{l}\text { 2002-2009: The SARS crisis and change of } \\
\text { administration opened a window for disruptive } \\
\text { policies. Policy guidelines shifted towards } \\
\text { universal coverage, in which primary care was } \\
\text { emphasized as a key area for strengthening. The } \\
\text { reform fell short of developing substantial and } \\
\text { coordinated policies to strengthen primary care. }\end{array}$ \\
\hline $\begin{array}{l}\text { Post- } \\
\text { juncture } \\
\text { development }\end{array}$ & $\begin{array}{l}\text { 1968-1978: Policies to shift professional } \\
\text { doctors to rural areas faced resistance. Primary } \\
\text { care policies eventually placed a further } \\
\text { emphasised on rural self-sufficiency with } \\
\text { strong rhetorical packaging, leaving rural } \\
\text { primary care weakly institutionalized. }\end{array}$ & $\begin{array}{l}\text { 2009-2018: Greater control was introduced of } \\
\text { primary care expenditure and services, but } \\
\text { Although restrictive policies at primary care } \\
\text { facilities had been introduced, hospital payment } \\
\text { reform was delayed. Continued lack of human } \\
\text { capital accumulation in primary care affected } \\
\text { patient confidence in and demand for community } \\
\text { services. Rapidly growing government financial } \\
\text { input support in health channeled funding } \\
\text { disproportionately towards hospitals and relatively } \\
\text { weakened primary care providers. }\end{array}$ \\
\hline
\end{tabular}

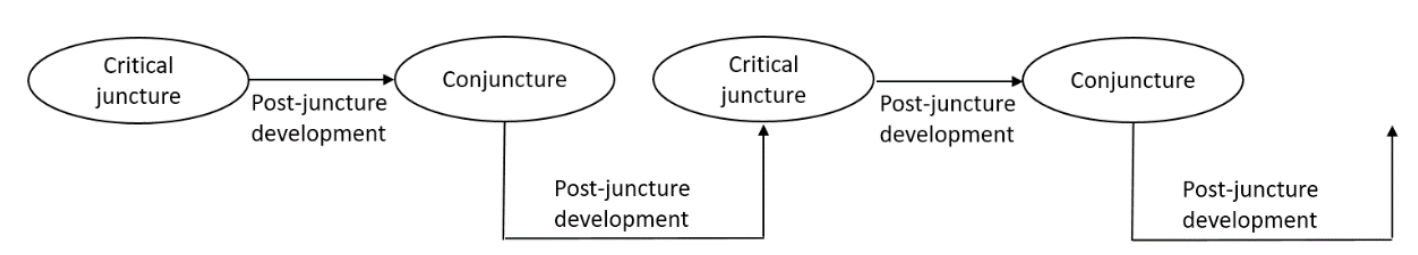

Figure 1. A model of cyclic path dependence

Each cycle started with a critical juncture rising amid a radically changing societal context (see Figure 1), where institutions favouring hospitals were initiated or renewed. This critical juncture was followed by a downstream process of self-reinforcement enhancing the hospitals' dominance. Later in each cycle, a conjuncture emerged to revise the previous system logic, coming into the existing prohospital institutional environment, that exhibited strong resilience. Hence, the repeated conjunctures failed to build primary care facilities on strong institutional grounds, and led to post-juncture processes which prompted the development of primary care as the antithesis of hospitals in both cycles. The weakness of such institutionalization turned into disadvantage for primary care when the next cycle started.

The re-emergence of policy junctures (i.e. critical junctures and conjunctures), and the repeated 
constraints from pre-existing system logic, characterise the coevolution of hospitals and primary care providers in China, suggesting that the path dependence exhibited in China's health system does not preclude major policy changes. Indeed, primary care strengthening was incorporated into key government policies at the conjunctures discussed above, unlike the repeated frustration of efforts to develop national health insurance in the United States (Hacker 1998). From our analysis, a key factor was the tendency to respond to short-term policy needs at critical junctures, which created potentially adverse and irreversible consequences. Neither continuity (Lucas 1982) nor radical changes (Huang 2013) suggested in earlier literature were sufficient to explain contemporary hospital dominance in China.

Instead, this imbalance is to a large extent the result of four interrelated sets of institutions formed in the 1950s and reshaped over the years. Professionally, a strong bonding of professional doctors was forged with hospitals. Organisationally, large outpatient departments allowed hospitals to profit from directly-accessing patients and precluded interdependence between hospitals and primary care providers. Financially, an urban-bias with a revenue-generating incentive and technology-based cross-subsidization, introduced to encourage expansion of medical services, channelled resources primarily to hospitals. In terms of governance, hospital growth went beyond effective policy control amid a generally fragmented regulatory landscape. These four sets of institutions provided the model of hospital development based on technology, extra-budgetary revenue, and strong backing (or demand) from powerful interests. This structure has been adaptively self-replicating.

\section{Policy implications}

The growing challenge of covering China's health expenditures by continuously increasing public spending (Zhai, Goss et al.) against a backdrop of economic slowdown is likely to open up another conjuncture aiming to increase the efficiency of health systems and contain cost escalation. Recently, China's leadership has made strong political commitment to prioritization of people's health in development with a focus on primary care (Xinhua Agency 2016). As historical experiences suggest, political commitment is important, yet dealing with the various challenges facing primary care strengthening in China requires systemic solutions.

The first priority is to contain hospital growth in order to break down the self-reinforcement of hospital centrism and allow the fiscal space for primary care development. The recent rapid expansion of hospitals reflected weak regional health planning on one hand, and inflationary payment mechanisms on the other. Payment reform should be prioritized to contain the demand of inpatient services. Revising the high-powered incentives seems critical in controlling supply-induced demand. Further, bundling of payment between hospital outpatient services and primary care providers may be needed to incentivize hospitals to transfer services to primary care where costs can be lower if patients are managed well. Hospitals should be repositioned to focus less on delivering a large volume of highly specialized treatment and more on quality of care, health management and support for primary care.

Second, strengthening of primary care requires both demand-side and supply-side efforts. Both sufficiently high salaries and promising career paths are needed to attract and retain capable staff at primary care facilities. A substantial number of highly qualified general practitioners are needed, as well as coherent human resources policies which provide salary and career prospects for primary care providers comparable to those of hospitals (Keck and Reed 2012, Macinko and Harris 2015). A teambased approach in primary care, as in Brazil, involving both highly qualified primary care professionals and community-based health workers, seems a sensible option for China in the near future. Such an approach not only uses a limited number of general practitioners efficiently, but also connects health workers in the community with health professionals (Harris and Haines 2010). Primary care facilities should be incrementally charged with coordinating care for residents. On the demand side, the value of primary care should be demonstrated with easy access to services that address the multiple health and functional conditions widely seen among the elderly and chronically ill patients as China becomes an aged society.

Third, more equitable pooling and strategic purchasing is needed along with more streamlined and autonomous governance of health service providers. On the one hand, the recent establishment of the 
National Healthcare Security Administration should shift purchasing of services towards addressing population health needs. Further consolidation and equalization is needed to allow rural and urban primary care facilities adequate resources. On the other hand, an administrative structure at the local level with sufficient authority to coordinate the various sets of institutions encompassing both hospitals and primary care facilities is needed. Given the interrelatedness of the reform elements mentioned above, it is probably better to start reform bottom up, from local areas. The central and local governments could work together to establish special health reform zones, where local leaders can have substantial autonomy to coordinate stakeholders and implement systemic reform.

Fourth, the doctors and patients need to be engaged more clearly than has historically been the case in future reform. We have argued above that the divergence between professional doctors and primary care contributed to contemporary weak primary care. Currently, doctors are mostly hired by public facilities and are rarely outspoken in organised ways about their interests, reflecting substantial barriers to open discussion about salary levels. A possible result of strong dominance of public purchasing in such a system during a relatively constrained economic period is the potential for overemphasis on cost containment of public expenditures. Gaal and McKee (2004) argued that informal payment became prevalent in Hungary because "the channels of exit and voice are blocked". International experiences in this area suggests the importance of the buy-in of medical professionals to introducing pro-primary-care changes. In Thailand, a rural doctors' association played a critical role in advocating for equitable payment for rural primary care doctors (Wibulpolprasert and Pengpaibon 2003). Experiences from rich countries in the area of integrated care where doctors change from concentrating on treatment of episodic care to integrated care also suggest the importance of leadership of clinical professionals (Amelung, Chase et al. 2017). These international experiences show the importance of ownership by medical professionals in introducing pro-primary-care changes.

Finally, given the intractability of the challenges facing primary care strengthening, disruptive technologies may have an important role to play. The lesson from the 1960s, in rapidly rolling out services when professional care was limited is to make good use of resources that can be reallocated relatively independently of reforms. Artificial intelligence and telemedicine offer new opportunities of "barefoot doctors of our time" in overcoming the path dependence of hospital-centrism. Meanwhile, as our paper has demonstrated, such disruption, if managed problematically, might also further alienate doctors and undermine the professional basis of primary care.

\section{Conclusion}

This study has explored the institutional coevolution of hospitals and primary care providers in China between 1949 and 2018 through the lens of path dependence analysis. We constructed a dynamic and cyclic path dependence model to explain the formation of hospital dominance and imbalance between hospitals and primary care providers. There have been two main cycles of path dependence involving a process of "critical juncture — post-juncture development — conjuncture — post-juncture development" since 1949, which eventually resulted in the professional, financial, governance-related and organizational institutions underlying the balance between hospitals and primary care providers. The development of an institutional complex related to the balance between hospitals and primary care providers suggested a dominance of hospitals underpinning the coevolution of hospitals and primary care providers.

Our findings suggest that primary care strengthening is unlikely to be successful without a comprehensive set of policy reforms at both central and especially local levels, coordinated and sustained over a substantial period. Amid drastic social transformation, it is important to maintain a strong commitment towards primary care, as neglect during rapid changes might be very difficult to reverse. The apparent path dependence of hospital centrism in China was not rooted in the absence of windows of policy change. Instead, one key source of path dependence seems to be the pre-existing system logic that survived the conjunctures. A fundamental shift of balance from hospitals to primary care providers requires a strong coalition of professional, bureaucratic and community stakeholders and a policy mix covering professional, financial, organisational and governance actions. 
Overall, a path dependence framework was helpful in making sense of the persistence of hospitalcentrism in China between 1949 and 2018, by identifying a long term and cyclical logic grounded in history. 


\section{References}

Aaron, H. (1967). Social Security: International Comparisons. Studies in the Economics of Income Maintenance. O. Eckstein. Washington, Brookings Institution.

Amelung, V., D. Chase and A. Reichert (2017). Leadership in Integrated Care. Handbook Integrated Care. V. Amelung, V. Stein, N. Goodwin et al. Cham, Switzerland, Springer International Publishing.

Beijing Municipal Government (2017). Annoucement on Issuing the Implementation Plan on Comprehensive Reform to Separate Pharmaceutical Sales and Medical Services.

Beijing Municipal Health Bureau (1973). The Bureau's Proposal and Report on Reinforcing Rural Health Work and Converting Collective Members of Rural Medical Team into State Employees (Benju guanyu jiaqiang nongcun weisheng gongzuo, nongcun yiliaodui jiti renyuan zhuanwei guojia zhigong deng gongzuoe de qingshi, baogao) (in Chinese).

Beijing Municipal Health Bureau (1973). Development of Health Work in Beijing in 1972 and Key Points for Work in 1973 (Beijingshi 1972 nian weisheng gongzuo fazhan qingkuang he 1973 nian gongzuo yaodian) (in Chinese).

Berridge, V. (2011). Using history in policy and practice. Public Health in History. V. Berridge, M. Gorksky and A. Mold. Berkshire, England, Open University Press.

Bhattacharyya, O., D. Yin, S. T. Wong and B. Chen (2011). "Evolution of primary care in China 1997 2009." Health Policy 100(2-3): 174-180.

Bloom, G. (1998). "Primary health care meets the market in China and Vietnam." Health Policy 44(3): 233-252.

Bloom, G. (2004). China in Transition: Challenges to Urban Health Services. Health care transition in urban China, . G. Bloom and S. Tang. Aldershot, England, Ashgate Publishing, Ltd.

Bloom, G. (2014). "History, complexity and health systems research." Social science \& medicine 117: 160-161.

Cao, W. (1955). Stopping the serious waste in publicly funded medical care (zhizhi gongfeiyiliao zhong de yanzhong langfei) (in Chinese). People's Daily (renmin ribao).

Capoccia, G. (2015). "Critical Junctures and Institutional Change." Advances in Comparative Historical Analysis: 147-179.

Central Committee of Communist Party of China (2018). Plan on Deepening Reform of Explanation of Party and State Institutions.

Central Committee of Communist Party of China and State Council. (2009). "Guanyu shenhua yiyao weisheng tizhi gaige de yijian [关于深化医药卫生体制改革的意见](Opinions on Deepening Health System Reform)." Retrieved February 6, 2013

Chen, C. C. (1989). Medicine in rural China: a personal account, Univ of California Press.

Chen, H. and S. Xu (1984). Chinese Medical Encyclopedia--Social Medicine and Health Management Sciences (Zhongguo Yixue Baikequanshu--Shehui Yixue yu Weisheng Guanlixue) (in Chinese). Shanghai, Shanghai Science and Technology Press.

China National Health Development Research Center (2017). China National Health Accounts Report 2017.

Collier, D. and R. E. Messick (1975). "'Prerequisites Versus Diffusion: Testing Alternative Explanations of Social Security Adoption'." The American Political Science Review 69(4).

Commentator (1965). An important approach of popularizing rural medical and health services (Puji nongcun yiliao weisheng gongzuo de zhongyao tujing) (in Chinese). People's Daily (Renmin ribao). 
Deng, T. and Z. Cheng (2000). Jindai juan (Modern times volume) (in Chinese), People's Medical Publishing House.

Duckett, J. (2012). The Chinese state's retreat from health: Policy and the politics of retrenchment, Routledge.

Editorial (1977). Carrying out well university admission is the hope of the whole nation (Gaohao daxue zhaosheng shi quanguo renmin de xiwang) (in Chinese). People's Daily (Renmin Ribao).

Editorial Office of the Red Flag Magazine (1968). "Seeing the direction of medical education reform from the growth of "barefoot docotrs" in Jiangzhen Commune (Cong Jiangzhen gongshe "chijiao yishen" de chengzhang kan yixue jiaoyu geming de fangxiang) (in Chinese)." Red Flag (Hongqi).

Fang, X. (2012). Barefoot Doctors and Western Medicine in China, University of Rochester Press.

Flora, P. and J. Alber (1981). The Development of Welfare States in Western Europe. The Development of Welfare States in Europe and America, . P. Flora and A. J. Heidenheimer. London, Transaction Books: 37-80.

Fu, Y. (2011). "Analysis of situation and influencing factors regarding employment of medical students from Zhongshan Hospital, Fudan University." Chinese Medical Education Journal 31(2).

Gaal, P. and M. McKee (2004). "Informal payment for health care and the theory of 'INXIT'." (0749-6753 (Print)).

General Office of Central Committee of Communist Party of China and General Office of State Council (1993). Guanyu sheji nongmin fudan xiangmu shenhe chuli yijian de tongzhi (关于涉及农民负担项目审核处理意见的通知) [Circular on opinions regarding approval and handling of programmes involving burden on peasants]

General Office of the State Council (2018). Reforming and Perfecting Cultivation and Motivation Mechanisms for General Practitioners.

Global Conference, o. P. H. C. (2018). Declaration on Primary Health Care.

Gross, M. (2018). "Between Party, People, and Profession: The Many Faces of the 'Doctor' during the Cultural Revolution." Med Hist 62(3): 333-359.

Gusmano, M. K. (2015). China. Comparative Health Care Federalism. K. Fierlbeck; and H. A. Palley. Farnham, England, Ashgate Publishing Limited.

Hacker, J. S. (1998). "The historical logic of national health insurance: Structure and sequence in the development of British, Canadian, and US medical policy." Studies in American Political Development 12(01): 57-130.

Harris, M. and A. Haines (2010). "Brazil's Family Health Programme." BMJ 341: c4945.

Henderson, G. (1989). Issues in the modernisation of medicine in China. Science and Technology in Post-Mao China. D. F. Simon and M. Goldman. Harvard, Harvard University Press: 199-221.

Hu, A. (2012). "China, Social Insurance and the Welfare State: A Global Historical Perspective." World History Connected(1).

Hu, D., C. Chen, C. Zhang, M. Huang, J. Wang, Z. Jia, H. Li and X. Liu (2018). "Effectiveness and challenges of targeted admission medical education program in rural China." Chinese Journal of Health Policy 11(9): 28-33.

Huang, Q. (2013). Some High-level Executives of GlaxoSmithKline (China) were prosecuted (Gelansushike (zhongguo) bufen gaoguan bei lian zhencha: jiekai kuaguo yaoqi shangye huilu liyilian) (in Chinese). People's Daily (Renmin Ribao). Beijing.

Huang, Y. (1957). "Issues and Opinions on Improvement of the Current Fund Management of Publicly Funded Medical Care (dangqian gongfei yiliao jingfei guanli zhong de wenti he gaijin yijian) (in Chinese)." Finance (caizheng)(3): 15-17.

Huang, Y. (2013). Governing health in contemporary China, Routledge. 
Jiangxi Provincial Health Gazette Compiling Committee (1997). Jiangxi Provincial Health Gazette. Hefei, Jiangxi, Huangshan Shushe.

Keck, C. W. and G. A. Reed (2012). "The curious case of Cuba." Am J Public Health 102(8): e13-22.

Li, S. (1997). The problems of hospital reimbursement and related suggestions. Jinan.

Liang, S., L. He, S. Song, Y. Jin, B. Yuan and Q. Meng (2016). "Analysis of Typical Cases of Development and Practice of Integrated Delivery System of Health Care in China." Chinese Journal of Health Policy 9(5): 42-48.

Litsios, S. (2015). On the Origins of Primary Health Care. Health for All--The Journey to Universal Health Coverage. A. Medcalf, S. Bhattacharya, H. Momen, M. Saavedra and M. Jones. Hyderabad, Orient Blackswan Pvt. Ltd. .

Liu, R. (1957). "How to turn deficit of publicly funded medical care into surplus (gongfei yiliao zenyang cong chaozhi bianwei youyu) (in Chinese)." Finance (caizheng)(10): 32.

Liu, X., Y. Liu and N. Chen (2000). "The Chinese experience of hospital price regulation." Health Policy and Planning 15(2): 157-163.

Liu, X. and A. Mills (2005). "The effect of performance-related pay of hospital doctors on hospital behaviour: a case study from Shandong, China." Human Resources for Health 3(11).

Liu, X., L. Xu and S. Wang (1996). "Reforming China's 50000 township hospitals-effectiveness, challenges and opportunities." Health Policy 38(1): 13-29.

London, J. D. (2014). "Welfare Regimes in China and Vietnam." Journal of Contemporary Asia 44(1): 84-107.

Lucas, A. (1982). Chinese medical modernization: Comparative policy continuities, 1930s-1980s, Praeger.

Luo, Z. and J. Sun (1992). Beijing yike daxue de bashinian (The Eight Decades of Beijing Medical University). Beijing, Peking University Medical Press.

Ma, X., H. Wang, L. Yang, L. Shi and X. Liu (2019). "Realigning the incentive system for China's primary healthcare providers." BMJ 365: 12406 .

MacFarquhar, R. and J. Fairbank (1987). The Cambridge History of China: Volume 14, The People's Republic, Part 1, The Emergence of Revolutionary China, 1949-1965. New York, Cambridge University Press.

MacFarquhar, R. and J. Fairbank (1991). The Cambridge History of China: The People's Republic, Pt. 2: Revolutions Within the Chinese Revolution, 1966-1982, New York: Cambridge University Press.

Macinko, J. and M. J. Harris (2015). "Brazil's Family Health Strategy - Delivering Community-Based Primary Care in a Universal Health System." 372(23): 2177-2181.

Mao, Z. (1949). Zai zhongguo gongchandang diqijie zhongyang weiyuanhui di'erci quanti huiyi shang de baogao (在中国共 产党第七届中央委员会报告第二次全体会议上的报告) [Report to the Second Plenary of the Seventh Central Committee of the Chinese Communist Party].

Ministry of Health (1950). "Directives on Medical Administration Work This Year." Shandong Policy Paper (Shandong zhengbao)(05): 81.

Ministry of Health (1951). "Central People's Government Issued Four Decisions of the National Health Congress Regarding Medicines, Education, etc 中央人民政府卫生部公布全国卫生大会关于医药教育等四项决定." Traditional Chinese Medicine Journal(01): 1-5. 
Ministry of Health (1951). Detailed Implementation Plan of Work on Rural Health Organization (Draft) (Nongcun weisheng jiceng zuzhi gongzuo juti shishi banfa (cao'an)). Collection of Rural Health Policy Documents (1951-2000). K. L. Changming Li, Zhaoyang Zhang, Chunlei Nie, Wei Fu, Hongming Zhu, Bin Wang, Department Grassroot Health and Marternal and Child Health, Ministry of Health: 241-251.

Ministry of Health (1951). "On Implemention Measures of Organizing United Health Facilities."

Ministry of Health (1957). Directive on Strengthening Leadership of Grassroot Health Organisations. Collection of Rural Health Policy Documents (1951-2000). K. L. Changming Li, Zhaoyang Zhang, Chunlei Nie, Wei Fu, Hongming Zhu, Bin Wang, Department Grassroot Health and Marternal and Child Health, Ministry of Health.

Ministry of Health (1957). Guanyu gaijin huaqu yiliao fuwu gongzuo de zhishi [关于改进划区医疗服务工作的指示] (Directives on improving sectional medical services).

Ministry of Health (1959). Opinions on several issues regarding health work in people's communes (guanyu renmin gongshe weisheng gongzuo jige wenti de yijian) (in Chinese).

Ministry of Health (1960). Report on the National Rural Health Field Conference in Qishan, Shanxi (Guanyu quanguo nongcun weisheng gongzuo Shanxi Qishan xianchagn huiyi qingkuang de baogao) (in Chinese).

Ministry of Health (1962). Opinions on improving several issues related to hospital work (Guanyu gaijin yiyuan gongzuo ruogan wenti de yijian) (in Chinese).

Ministry of Health (1965). Report on puting the stress of health work in rural areas (Guanyu ba weisheng gongzuo zhongdian fangdao nongcun de baogao) (in Chinese).

Ministry of Health (1974). "1973 nian quanguo jiaoyu weishegn he xingzheng zuotanhui fujian san ·Guanyu weisheng shiye jihua caiwu gongzuo zhong ruogan wenti de yijian (zhaiyao) (1973 年全国教育卫生和行政座谈会附件三·关于卫生事业

计划财务工作中若干问题的意见 (摘录) ) [1973 National Administrative Group Discussion on Education and Health, third attachment--Opinions regarding issues in health affairs planning and financial work].".

Ministry of Health (1980). Opinions regarding carrying out rectification and construction of health affairs in about one third of counties (guanyu gaohao sanfen zhiyi zuoyou xian de weisheng shiye zhegndun jianshe de jidian yijian) (in Chinese).

Ministry of Health (1980). Opinions regarding strengthening work of county hospitals (Guanyu jiaqiang xianyiyuan gongzuo de jidian yijian) (in Chinese).

Ministry of Health (1989). Health Statistics Informaiton in China 1949-1988 建国四十年--全国卫生统计资料.

Ministry of Health (1990). The Eighth Five-year Plan for Health Work and Planning Proposal for 2000 (Weisheng shiye dibage wunian jihua ji erlinglingling nian guihua shexiang).

Ministry of Health (2003). China Health Statistical Yearbook 2003. Beijing, Peking Union Medical College Publishing House.

Ministry of Health, Ministry of Finance and State Administration of Traditional Chinese Medicine (2007). Guiding opinions regarding perfecting measures of pooling and reimbursement of the New Rural Cooperative Medical Scheme (Guanyu wanshan xinxing nongcun hezuoyiliao tongchou buchang fang'an de zhidao yijian) (in Chinese).

Ministy of Health, Ministry of Finance and State General Administration of Labour (1979). "Circular on Strengthening Hospital Economic Management Piloting Work (Guanyu jiaqiang yiyuan jingji guanli shidian gongzuo de tongzhi) (in Chinese)."

National Bureau of Statistics of China (1989). China Statistical Yearbook 1989. Beijing, China Statistics Press 
National Health and Family Planning Commission (2017). China Health and Family Planning Statistical Yearbook 2017. Beijing, Beijing Union Medical University Press.

National Health and Family Planning Commission, Ministry of Finance, State Commission Office for Public Sector Reform, National Development and Reform Comission, Ministry of human Resources and Social Security, State Administration of Traditional Chinese Medicine and State Council Office of Health Reform (2017). Annoucement on Rolling-Out Comprehensive Reform of Public Hospitals in All Aspects (Guanyu Quanmian Tuikai Gongli Yiyuan Zonghe Gaige Gongzuo de Tongzhi).

Party Branch of Heidouyu Brigade at Huangsongyu Commune (1977). Jianchi sixiang zhengdun, jianshe geminghua weishengyuan (坚持思想整顿 建设革命化卫生院) [holding on to thought correction, building revolutionalized a health centre]

Pierson, P. (1993). "When effect becomes cause: Policy feedback and political change." World politics 45(04): 595-628.

Pierson, P. (2000). "Increasing returns, path dependence, and the study of politics." American political science review: 251267.

Pierson, P. and T. Skocpol (2002). "Historical institutionalism in contemporary political science." Political science: The state of the discipline 3

Pinggu Health Bureau (1975). "Statistics of Barefoot Doctors Trained between 1965 and 1975."

Pinggu Health Bureau (1986). Pinggu Health Gazette.

Qian, X. (1988). "Historical Experience in Health Management in China (Zhongguo weisheng guanli de lishi jingyan) (in Chinese)." Chinese Social Medicine.

Renshaw, M. (2014). The Evolution of the Hospital in Twentieth-Century China. Medical Transitions in Twentieth-Century China. B. Andrews and M. B. Bullock. Bloomington \& Indianapolis, Indiana University Press.

Revolutionary Committee of Leyuan Commune (1968). We get firm hold of three major issues--experiences on implementing coopeartive medical scheme in Leyuan Commune (Women henzhua le sanjian dashi--leyuan gongshe shixing hezuo yiliao zhidu de jingyan) (in Chinese). People's Daily (Renmin ribao).

State Council (1963). State Council's Approval and Reply to Ministry of Health Report on Issues Concerning Special Fund for Medical Relief in Rural Areas (Guowuyuan pifu weishegnbu guanyu nongcun yiyao jiuji zhuankuan wenti de baogao) (in Chinese).

State Council (1981). Cicular on approving and forwarding Ministry of Health's Report on Appropriately Solving the Subsidy for Barefoot Doctors.

State Council (1985). Cicular on Approving and Forwarding Ministry of Health's Report on Several Policy Issues Related to Health Work Reform (Guowuyuan pizhuan weishengbu guanyu weisheng gongzuo gaige ruogan zhegnce wenti baogao de tongzhi) (in Chinese).

State Council (1989). Opinions on Issues Related to Expanding Medical and Health Services (Guanyu kuoda yiliao weisheng fuwu youguan wenti de yijian) (in Chinese)

State Council (1992). Some Opinions Regarding Deepening Health Reform (Guanyu shenhua weisheng gaige de jidian yijian) (in Chinese).

State Council (1998). Decision regarding establishing urban employees basica medical insurance scheme (Guanyu jianli chengzhen zhigong jiben yiliao baoxian zhidu de jueding) (in Chinese). 
State Council (2000). "Guiding Opinions on Urban Health System Reform (Guanyu chegnzhen yiyao weisheng tizhi gaige de zhidao yijian) (in Chinese)."

State Council (2009). Guowuyuan guanyu yinfa yiyao weishegn tizhi gaige jinqi zhongdian shishifangan (2009-2011nian) de tongzhi [国务院关于印发医药卫生体制改革近期重点实施方案（2009-2011 年) ] (The State Council's circular regarding the implementation plan for key points of health system reform in the near future (2009-2011)).

Tang, S. and Q. Meng (2004). Introduction to the Urban Health System and Review of Reform Initiatives. Health Care Transition in Urban China. G. Bloom and S. Tang. Hampshire, England, Ashgate Publishing Ltd.

Tuohy, C. H. (1999). Accidental Logics: The Dynamics of Change in the Health Care Arena in the United States, Britain, and Canada, Oxford University Press.

Wang, G., J. Yu, J. Zhang and Y. Wang (2015). A 60-year History of Disease Prevention and Control in China; China Population Publishing House Beijing, China Population Publishing House.

Wang, H., M. K. Gusmano and Q. Cao (2011). "An evaluation of the policy on community health organizations in China: will the priority of new healthcare reform in China be a success?" Health policy 99(1): 37-43.

Wibulpolprasert, S. and P. J. H. R. f. H. Pengpaibon (2003). "Integrated strategies to tackle the inequitable distribution of doctors in Thailand: four decades of experience." 1(1): 12.

Wilsford, D. (1994). "Path dependency, or why history makes it difficult but not impossible to reform health care systems in a big way." Journal of public policy: 251-283.

World Bank (1992). China: Long-Term Issues and Options in the Health Transition. Washington, D.C., The World Bank: 133.

World Health Organization (2000). The world health report 2000: health systems: improving performance, WHO.

World Health Organization (2008). The world health report 2008: primary health care: now more than ever. Geneva, World Health Organization.

Xinhua Agency. (2016). "National Health Congress held in Beijing on 19th and 20th September " Retrieved 1 January 2019 from http://www.gov.cn/xinwen/2016-08/20/content 5101024.htm.

Xu, J., M. Gorsky and A. Mills (2019). "Historical roots of hospital centrism in China (1835-1949): A path dependence analysis." Social Science \& Medicine 226: 56-62.

Xu, J. and A. Mills (2017). "Challenges for gatekeeping: a qualitative systems analysis of a pilot in rural China." Int J Equity Health 16(1): 106

Xu, J. and A. Mills (2019). "The rise of hospital dominance in China (1949-2016): a historical trend analysis of the balance between hospitals and primary care providers." unpublished manuscript.

Yin, Y. (1955). Overcoming the phenomena of waste in publicly funded medical care (kefu gongfei yiliao zhong de langfei xianxiang) (in Chinese). People's Daily (renmin ribao).

Yip, W., H. Fu, A. T. Chen, T. Zhai, W. Jian, R. Xu, J. Pan, M. Hu, Z. Zhou, Q. Chen, W. Mao, Q. Sun and W. Chen (2019). "10 years of health-care reform in China: progress and gaps in Universal Health Coverage." Lancet 394(10204): 1192-1204.

Yip, W. and W. Hsiao (2009). "How effective is China's new cooperative medical scheme in reducing medical impoverishment?" Social Science \& Medicine 68: 201 - 209.

Zhai, T., J. Goss and J. Li "Main drivers of health expenditure growth in China: a decomposition analysis." (1472-6963 (Electronic)). 
Zhang, D. and P. U. Unschuld (2008). "China's barefoot doctor: past, present, and future." The Lancet 372(9653): $1865-1867$.

Zhang, M. and Y. Bian (2007). "Retrospect of the Policy of Drug Price Addition in Hospitals and Its Influences." Chinese Health Service Management 7(229): 465-466.

Zhang, Q. (1950). On constructing rural health services--notes of Rural Health Forum of Central Ministry of Health (Guanyu nongcun weisheng jianshe wenti--ji zhongyang weishengbu nongcun weisheng zuotanhui) (in Chinese). Renmin ribao (People's Daily).

Zhang, X. (1953). Health Affairs of the New China (xinzhongquo de weishegnshiye) (in Chinese). Beijing, Life. Reading.New Knowledge Three-United Bookstore (shenghuo·dushu·xinzhi sanlian shudian).

Zhang, Z. (1982). "Guanyu Jiaqiang Nongcun Weisheng Duiwu de Guanli he Jishu Peixun Wenti-Dongbei Sansheng Nongcun Yiliao Weisheng Jianshe Diaocha Zhi San (On Strengthening Management of Rural Health Workforce and Professional Training-Rural Health Construction Investigation in the Three Northeast Provinces, No. 3." Nongcun Weisheng Shiye Guanli Yanjiu (Rural Health Service Management Research) 2.

Zhang, Z. (2006). "Review and comments on the historical situation related to the "June 26th Directive"." Chinese Rural Health Care Management 中国农村卫生事业管理 26(9): 9-12.

Zheng, L. (2013). Unveiling the series corruption cases in pharmaceutical procurement and sales Zhangzhou: half of drug prices is used on "public relationships" (Zhangzhou yiliao gouxiao lingyu fubai wo'an daqidi: yaojia yiban yongyu "gongguan"). People's Daily (Renmin Ribao).

Zhou, X. (2016). "Reconsidering the Barefoot Doctor Programme." Fudan Journal of the Humanities and Social Sciences 9(1) $41-63$.

Zhou, X. D., L. Li, T. Hesketh, Q. Liu, X. Tian, J. Tian and X. Zhang (2014). "Health system reform in rural China: Voices of healthworkers and service-users: Evaluation of the effects of comprehensive reform on primary healthcare institutions in Anhui Province." Social Science \& Medicine 117: 134. 